\title{
MENENTUKAN BILANGAN KROMATIK LOKASI PADA GRAF BERLAPIS $\mathrm{C}_{n, 2 n, 2 n}$
}

\author{
PUTRI WAHYU AISYIAH, NARWEN, ZULAKMAL \\ Program Studi Matematika, \\ Fakultas Matematika dan Ilmu Pengetahuan Alam, Universitas Andalas, \\ Kampus Unand Limau Manis, Padang, Indonesia \\ email: putriwahyuaisyiah@gmail.com
}

\begin{abstract}
Abstrak. Bilangan kromatik lokasi adalah bilangan terkecil $k$ sehingga $G$ mempunyai pewarnaan- $k$ lokasi. Kelas warna pada $G$ dinotasikan dengan $C_{i}$, merupakan himpunan titik-titik yang berwarna $i$ dan $1 \leq i \leq k$. Misalkan $\Pi=\left\{C_{1}, C_{2}, \cdots, C_{k}\right\}$ merupakan partisi terurut dari $V(G)$ berdasarkan suatu pewarnaan titik, maka representasi v terhadap $\Pi$ disebut kode warna dari $v$ dinotasikan dengan $c_{\Pi}(v)$. Kode warna $c_{\Pi}(v)$ dari suatu titik $v \in V(G)$ didefinisikan sebagai vektor- $k$ :
\end{abstract}

$$
c_{\Pi}(v)=\left(d\left(v, C_{1}\right), d\left(v, C_{2}\right), \cdots, d\left(v, S_{k}\right)\right)
$$

dimana $d\left(v, C_{i}\right)=\min \left\{d(v, x) \mid x \in C_{i}\right\}$ untuk $1 \leq i \leq k$. Jika setiap titik yang berbeda di $G$ memiliki kode warna yang berbeda untuk suatu $\Pi$, maka $c$ disebut pewarnaan lokasi dari $G$.

Kata Kunci: Bilangan Kromatik Lokasi, Kode Warna, Graf Berlapis

$\begin{array}{lll}\text { Diterima } & : & \text { 26 Juli 2018 } \\ \text { Direvisi } & : & \text { 17 September 2018 } \\ \text { Dipublikasikan } & : & \text { 21 Desember 2018 }\end{array}$

\section{Pendahuluan}

Teori graf merupakan pokok bahasan salah satu ilmu matematika yang banyak mendapat perhatian karena model-modelnya sangat berguna untuk aplikasi yang luas, diantaranya diterapkan dalam jaringan komunikasi, transportasi, ilmu komputer, riset operasi, dan rancangan suatu bangunan. Banyak sekali penelitian terbaru tentang graf, dimensi partisi, pewarnaan lokasi.

Pewarnaan sisi- $k$ untuk $G$ adalah pemberian $k$ warna pada sisi-sisi $G$ sedemikian hingga setiap dua sisi yang bertemu pada titik yang sama mendapatkan warna berbeda. Pewarnaan titik pada graf adalah pemberian warna untuk setiap titik pada graf sehingga tidak ada dua titik yang bertetangga berwarna sama. Pewarnaan graf dengan penggunaan warna seminimal mungkin ini disebut bilangan kromatik lokasi dari graf $G$, dan disimbolkan dengan $\chi_{L}(G)$.

Konsep bilangan kromatik lokasi diperkenalkan pada tahun 2002 oleh Chartrand dkk. [2] sebagai pengembangan dari dua konsep dalam graf, yaitu pewarnaan titik pada graf dan dimensi partisi graf.

Chartrand dkk. [2] mendefinisikan bilangan kromatik lokasi sebagai berikut. Misalkan $G=(V, E)$ adalah graf terhubung dan $c$ suatu $k$-pewarnaan sejati dari 
$G$. Misalkan pula $\Pi=\left\{C_{1}, C_{2}, \cdots, C_{k}\right\}$ merupakan partisi dari $V(G)$ yang diinduksi oleh pewarnaan $c$. Kode warna $c_{\Pi}(v)$ dari $v$ adalah koordinat $c_{\Pi}(v)=$ $\left(d\left(v, C_{1}\right), d\left(v, C_{2}\right), \cdots, d\left(v, S_{k}\right)\right)$ dengan $d\left(v, C_{i}\right)=\min \left\{d(v, x) \mid x \in C_{i}\right\}$ untuk $1 \leq i \leq k$. Jika semua titik di $G$ mempunyai kode warna berbeda, maka $c$ disebut pewarnaan lokasi.

\section{Terminologi Graf}

Suatu graf $G$ adalah pasangan himpunan $V$ dan $E$, dituliskan $G=(V, E)$, dimana $V$ adalah suatu himpunan titik (vertex) yang tidak kosong dan $E$ adalah himpunan sisi (edge) yang terdiri dari pasangan terurut dari titik-titik berbeda dari $V$. Misalkan $V(G)=\left\{v_{1}, v_{2}, \cdots, v_{n}\right\}$ adalah himpunan titik yang berisi $n$ titik di $G \operatorname{dan} E(G)=$ $\left\{e_{1}, e_{2}, \cdots, e_{m}\right\}$ adalah himpunan sisi yang berisi $m$ sisi di $G$. secara umum, untuk menotasikan sisi dapat ditulis dengan $e=v_{i} v_{j}$ atau $e=v_{j} v_{i}$.

Kardinalitas dari himpunan $V(G)$ disebut orde pada $G$ dan kardinalitas dari himpunan $E(G)$ disebut ukuran (size) pada $G$. Derajat (degree) suatu titik di $G$ adalah banyaknya sisi yang terkait dengan $v$, dinotasikan dengan $\operatorname{deg}(v)$. Jika terdapat sisi $e$ yang menghubungkan titik $u$ dan $v$, maka $u$ dan $v$ disebut bertetangga. Titik-titik u dan v dari sisi e disebut sebagai titik-titik ujung (end vertices) dari sisi e. Sisi yang kedua titik ujungnya sama disebut loop. Bila ada lebih dari satu sisi yang menghubungkan dua buah titik maka sisi-sisi itu disebut sisi ganda (multiple edges). Graf yang tidak memiliki loop atau sisi ganda disebut graf sederhana (simple graph), dan graf $G$ dengan n titik yang setiap dua titiknya bertetangga disebut graf lengkap (complete graph) dinotasikan dengan $K_{n}$.

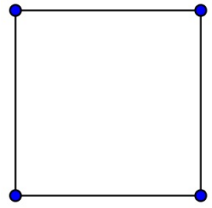

(a)

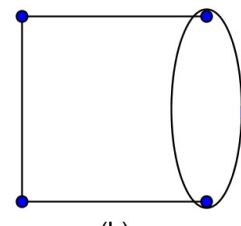

(b)

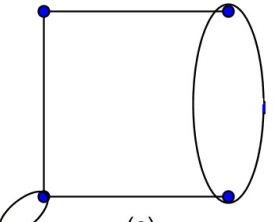

(c)

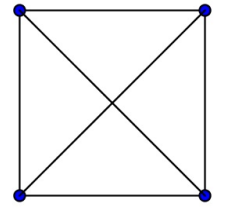

(d)

Gambar 1. (a) Graf sederhana, (b) Graf dengan sisi ganda, (c) Graf dengan loop dan sisi ganda, (d) Graf lengkap

Jalan (walk) dari titik $v_{0}$ ke titik $v_{n}$ di $G$ adalah barisan berhingga dari titiktitik dan sisi-sisi di $G$ yaitu $v_{0}, e_{1}, v_{1}, e_{2}, \cdots, e_{k}, v_{k}$ sedemikian sehingga, $v_{i-1} \in$ $E(G)$ untuk $i=1,2, \cdots, n$. Dalam hal ini, $v_{0}$ disebut titik awal (terminal vertex). Lintasan (Path) adalah suatu jalan yang menghubungkan antara dua titik dimana setiap titik dan sisi hanya dilewati satu kali. Misal $G$ adalah graf dengan himpunan titik $V(G)=\left\{v_{1}, v_{2}, \cdots, v_{n}\right\}$ dan himpunan $\operatorname{sisi} E(G)=\left\{e_{1}, e_{2}, \cdots, e_{n}\right\}$. Jarak antara dua titik $u$ dan $v$, dinotasikan dengan $d(u, v)$, adalah panjang lintasan terpendek dari titik $u$ ke $v$.

Graf lintasan merupakan suatu graf yang terdiri dari lintasan tunggal. Graf lintasan dengan $n$ titik dilambangkan dengan $P_{n}$. Graf lintasan dengan n titik memi- 
liki n-1 sisi.
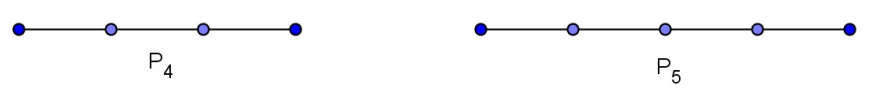

Gambar 2. Graf lintasan $P_{4}$ dan $P_{5}$

Dua titik $u$ dan $v$ di $G$ dikatakan terhubung jika terdapat lintasan $(u, v)$ di $G$. Graf $G$ dikatakan graf terhubung (connected graph) bila semua titik pada $G$ dapat dilewati dari setiap titik lainnya. Dengan kata lain, suatu graf dikatakan terhubung bila untuk setiap pasangan titik $u$ dan $v$ pada $G$ terdapat paling sedikit satu lintasan $(u, v)$ yang menghubungkan keduanya. Graf $g$ dikatakan graf tak terhubung (disconnected graph) bila ada suatu lintasan yang tidak menghubungkan titik $u$ ke $v$.

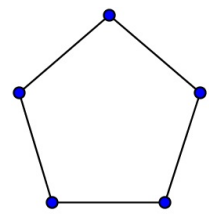

(a)

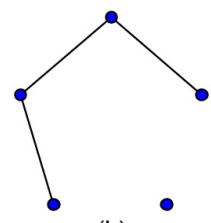

(b)

Gambar 3. (a) Graf terhubung, (b) Graf tak terhubung

Graf Pohon (tree) merupakan graf terhubung minimal, dimana penghapusan sembarang sisi akan mengakibatkan graf yang tersisa tak terhubung. Pohon juga merupakan graf sederhana, tidak mempunyai lingkaran dan hanya ada satu lintasan diantara setiap pasangan titiknya.

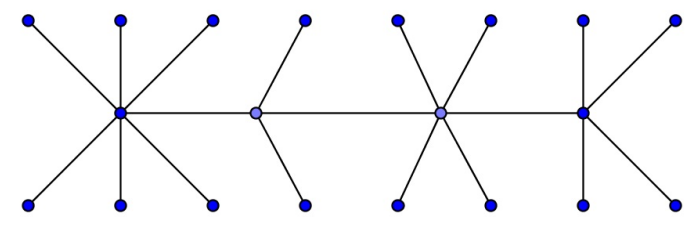

Gambar 4. Graf pohon

Graf Lingkaran (Cycle) disimbolkan dengan $C_{n} ; n \geq 3$, merupakan sebuah graf terhubung yang setiap titiknya berderajat dua. Banyak titik $C_{n}$ sama dengan banyak sisi $C_{n}$, yaitu $n$. 


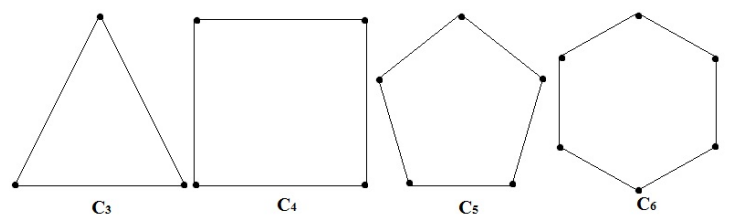

Gambar 5. Graf Lingkaran

\section{Bilangan Kromatik Lokasi pada Graf}

Teori pewarnaan graf merupakan suatu cabang teori graf yang mempelajari cara mewarnai suatu graf sedemikian sehingga tidak terdapat dua titik saling bertetangga pada graf tersebut yang berwarna sama. Pewarnaan titik adalah pemberian warna pada titik didalam graf sedemikian sehingga titik-titik bertetangga mempunyai warna berbeda. Pewarnaan- $k$ titik sejati dari graf $G=(V, E)$ adalah suatu pemetaan $c: V \rightarrow\{1,2, \cdots, k\}$ sedemikian sehingga $c(u) \neq c(v)$ jika $u$ dan $v$ bertetangga.

Kelas warna pada $G$ dinotasikan dengan $C_{i}$, merupakan himpunan titik-titik yang berwarna $i$ dan $1 \leq i \leq k$. Misalkan $\Pi=\left\{C_{1}, C_{2}, \cdots, C_{k}\right\}$ merupakan partisi terurut dari $V(G)$ berdasarkan suatu pewarnaan titik, maka representasi v terhadap $\Pi$ disebut kode warna dari $v$ dinotasikan dengan $c_{\Pi}(v)$. Kode warna $c_{\Pi}(v)$ dari suatu titik $v \in V(G)$ didefinisikan sebagai vektor- $k$ :

$$
c_{\Pi}(v)=\left(d\left(v, C_{1}\right), d\left(v, C_{2}\right), \cdots, d\left(v, C_{k}\right)\right)
$$

dimana $d\left(v, C_{i}\right)=\min \left\{d(v, x) \mid x \in C_{i}\right\}$ untuk $1 \leq i \leq k$. Jika setiap titik yang berbeda di $G$ memiliki kode warna yang berbeda untuk suatu $\Pi$, maka $c$ disebut pewarnaan lokasi dari $G$. Minimum dari banyaknya warna yang digunakan pada pewarnaan lokasi dari graf $G$ disebut bilangan kromatik lokasi. Karena setiap pewarnaan lokasi juga merupakan suatu pewarnaan, maka $\chi(G) \leq \chi_{L}(G)$.

Berikut ini Chartrand dkk. [2] telah memberikan teorema dasar dari bilangan kromatik lokasi suatu graf. Definisikan $N(u)$ sebagai himpunan yang berisi titik yang menjadi tetangga dari $u$ dan $N(v)$ sebagai himpunan yang berisi titik yang menjadi tetangga dari $v$.

Teorema 3.1. [2] Misal c adalah suatu pewarnaan lokasi pada graf terhubung $G$. Jika $u$ dan $v$ adalah dua titik pada graf $G$ sedemikian sehingga $d(u, w)=d(v, w)$ untuk setiap $w \in V(G) \backslash\{u, v\}$, maka $c(u) \neq c(v)$. Dalam hal khusus, jika $u$ dan $v$ adalah titik-titik yang tidak bertetangga di $G$ sedemikian sehingga $N(u)=N(v)$, $\operatorname{maka} c(u) \neq c(v)$.

Bukti. Misalkan $c$ adalah suatu pewarnaan lokasi pada graf terhubung $G$ dan misalkan $\Pi=\left(C_{1}, C_{2}, \cdots, C_{k}\right)$ adalah partisi dari titik-titik $G$ ke dalam kelas warna $C_{i}$. Untuk suatu titik $(u, v) \in V(G)$, andaikan $c(u)=c(v)$ sedemikian sehingga titik $u$ dan $v$ berada dalam kelas warna yang sama, misal $C_{i}$ dari $\Pi$. Akibatnya, $d\left(u, C_{i}\right)=d\left(v, C_{i}\right)=0$. Karena $d(u, w)=d(v, w)$ untuk setiap $w \in V(G) \backslash\{u, v\}$ 
140 Putri Wahyu Aisyiah, dkk.

maka $d\left(u, C_{j}\right)=d\left(v, C_{j}\right)$ untuk setiap $j \neq i, 1 \leq j \leq k$. Akibatnya, $c_{\Pi}(u)=c_{\Pi}(v)$ sehingga $c$ bukan pewarnaan lokasi. Dengan demikian, $c_{\Pi}(u) \neq c_{\Pi}(v)$.

Akibat 3.2. Jika $G$ adalah suatu graf terhubung yang memuat suatu titik yang bertetangga dengan $k$ daun di $G$, maka $\chi_{L}(G) \geq k+1$.

Bukti. Misalkan $v$ adalah suatu titik yang bertetangga dengan $k$ daun $x_{1}, x_{2}, \cdots, x_{k}$ di $G$. Dari Teorema 3.1 setiap pewarnaan lokasi dari G mempunyai warna berbeda untuk setiap $x_{i}, i=1,2, \cdots, k$. Karena $v$ bertetangga dengan semua $x_{i}$, maka $v$ harus mempunyai warna yang berbeda dengan semua daun $x_{i}$. Akibatnya, $\chi_{L}(G) \geq k+1$.

\section{Graf Berlapis $C_{n, 2 n, 2 n}$}

Graf berlapis $C_{n, 2 n, 2 n}$ merupakan suatu graf yang terbentuk dari tiga buah graf lingkaran dengan graf lingkaran pertama memiliki $n$ buah titik dan graf lingkaran kedua dan ketiga masing-masing memiliki $2 n$ buah titik. Dalam hal ini, himpunan titik dan himpunan sisi dari graf berlapis adalah:

$$
\begin{aligned}
V\left(C_{n, 2 n, 2 n}\right)= & V\left(C_{n}\right) \cup V\left(C_{2 n}\right) \cup V\left(C_{2 n}\right), \\
E\left(C_{n, 2 n, 2 n}\right)= & E\left(C_{n}\right) \cup E\left(C_{2 n}\right) \cup E\left(C_{2 n}\right) \cup\left\{a_{i} b_{2 i} \mid 1 \leq i \leq n\right\} \cup\left\{b_{2 i-1} d_{2 i-1} \mid 1 \leq i \leq n\right\} \\
= & \left\{a_{k} a_{k+1} ; k=1,2, \cdots, n-1\right\} \cup\left\{a_{1} a_{n}\right\} \cup\left\{b_{t} b_{t+1} ; t=1,2, \cdots 2 n-1\right\} \cup\left\{b_{1} b_{2 n}\right\} \\
& \cup\left\{d_{t} d_{t+1} ; t=1,2, \cdots, 2 n-1\right\} \cup\left\{d_{1} d_{2 n}\right\} \\
& \cup\left\{a_{i} b_{2 i} \mid 1 \leq i \leq n\right\} \cup\left\{b_{2 i-1} d_{2 i-1} \mid 1 \leq i \leq n\right\} .
\end{aligned}
$$

Teorema 4.1. Misalkan terdapat graf berlapis $C_{n, 2 n, 2 n}$ dengan $n \geq 3$. Maka bilangan kromatik lokasi dari graf berlapis $C_{n, 2 n, 2 n}$ adalah $n+1$.

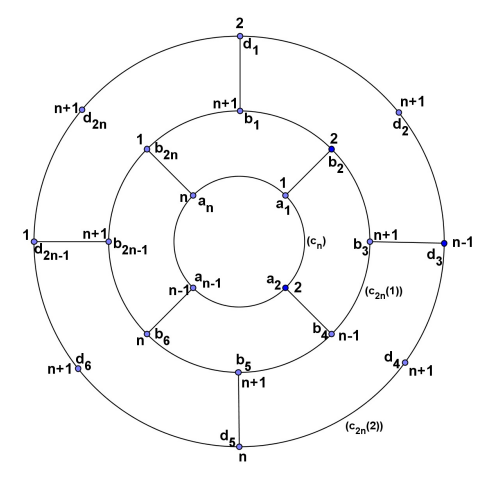

Gambar 6. Graf $\mathrm{C}_{n, 2 n, 2 n}$

Bukti. Himpunan titik dan himpunan sisi $C_{n, 2 n, 2 n}$ didefinisikan seperti pada (4.1) dan (4.2). Pandang dua kasus berikut. 
Kasus 1. $n=3$.

Notasikan $V\left(C_{3,6,6}\right)=\left\{a_{1}, a_{2}, a_{3}, b_{1}, b_{2}, b_{3}, b_{4}, b_{5}, b_{6}, d_{1}, d_{2}, d_{3}, d_{4}, d_{5}, d_{6}\right\}$. Definisikan partisi $\Pi=\left\{C_{1}, C_{2}, C_{3}\right\}$ sebagai berikut.

$$
\begin{aligned}
& C_{1}=\left\{a_{1}, b_{2}, b_{4}, d_{2}, d_{5}\right\}, \\
& C_{2}=\left\{a_{2}, b_{1}, b_{5}, d_{3}, d_{6}\right\}, \\
& C_{3}=\left\{a_{3}, b_{3}, b_{6}, d_{1}, d_{4}\right\} .
\end{aligned}
$$

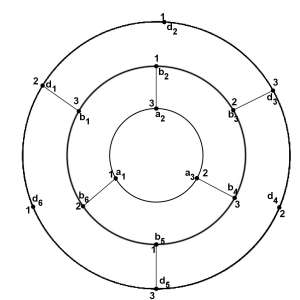

Gambar 7. Graf $C_{3,6,6}$

Karena $c_{\Pi}\left(a_{2}\right)=\left(d\left(a_{2}, C_{1}\right), d\left(a_{2}, C_{2}\right), d\left(a_{2}, C_{3}\right)\right)=(1,0,1)=c_{\Pi}\left(b_{1}\right)=(1,0,1)$ maka $\Pi$ bukan merupakan partisi yang tepat. Sehingga bilangan kromatik lokasi untuk graf berlapis $C_{n, 2 n, 2 n}$ dengan $n=3$ adalah 4 .

Kasus 2. $n \geq 4$.

Misalkan didefinisikan partisi $\Pi=\left\{C_{1}, C_{2}, \cdots, C_{n+1}\right\}$, dimana $C_{p}$ menyatakan kelas warna ke- $i$ untuk $1 \leq p \leq n+1$ sebagai berikut.

$$
\begin{aligned}
C_{1} & =\left\{a_{1}, b_{2 n}, d_{2 n-1}\right\} \\
C_{i} & =\left\{a_{i}, b_{2 i-2}, d_{2 i-3}\right\} ; i=2,3, \cdots, n \\
C_{n+1} & =\cup_{i=1}^{n}\left\{b_{2 i-1}, d_{2 i}\right\} .
\end{aligned}
$$

Kode warna untuk setiap titik pada graf $C_{n, 2 n, 2 n}$ sebagai berikut.

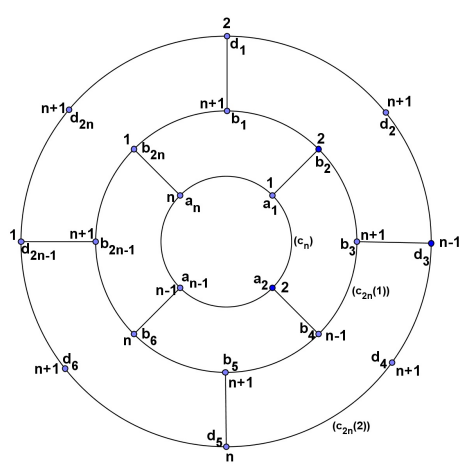

Gambar 8. Graf $C_{n, 2 n, 2 n}$ 


$$
\begin{aligned}
c_{\Pi}\left(a_{1}\right) & =\left(d\left(a_{1}, C_{1}\right), d\left(a_{1}, C_{2}\right), \cdots, d\left(a_{1}, C_{n}\right), d\left(a_{1}, C_{n+1}\right)\right)=(0,1, \cdots, 1,2), \\
c_{\Pi}\left(a_{2}\right) & =\left(d\left(a_{2}, C_{1}\right), d\left(a_{2}, C_{2}\right), \cdots, d\left(a_{2}, C_{n}\right), d\left(a_{2}, C_{n+1}\right)\right)=(1,0, \cdots, 2,2), \\
& \vdots \\
c_{\Pi}\left(a_{n}\right) & =\left(d\left(a_{n}, C_{1}\right), d\left(a_{n}, C_{2}\right), \cdots, d\left(a_{n}, C_{n}\right), d\left(a_{n}, C_{n+1}\right)\right)=(1,2, \cdots, 0,2), \\
c_{\Pi}\left(d_{2}\right) & =\left(d\left(d_{2}, C_{1}\right), d\left(d_{2}, C_{2}\right), \cdots, d\left(d_{2}, C_{n}\right), d\left(d_{2}, C_{n+1}\right)\right)=(3,1, \cdots, 4,0), \\
& \vdots \\
c_{\Pi}\left(d_{2 n}\right) & =\left(d\left(d_{2 n}, C_{1}\right), d\left(d_{2 n}, C_{2}\right), \cdots, d\left(d_{2 n}, C_{n}\right), d\left(d_{2 n}, C_{n+1}\right)\right)=(1,1, \cdots, 4,0) .
\end{aligned}
$$

Karena kode warna untuk setiap titik dari graf $C_{n, 2 n, 2 n}$ berbeda, maka $\chi_{L}\left(C_{n, 2 n, 2 n}\right) \leq n+1$.

Akan dibuktikan $\chi_{L}\left(C_{n, 2 n, 2 n}\right) \geq n+1$.

Andaikan banyaknya kelas warna graf $C_{n, 2 n, 2 n}$ adalah n dengan kelas warna sebagai berikut.

$$
\begin{aligned}
C_{1} & =\left\{a_{1}, b_{2}, b_{n+1}, d_{2}, d_{n+2}\right\}, \\
C_{2} & =\left\{a_{2}, b_{1}, b_{n+2}, d_{3}, d_{n+3}\right\}, \\
& \vdots \\
C_{n-1} & =\left\{a_{n-1}, b_{4}, b_{2 n-1}, d_{n}, d_{2 n}\right\}, \\
C_{n} & =\left\{a_{n}, b_{3}, b_{2 n}, d_{1}, d_{n+1}\right\} .
\end{aligned}
$$

Karena $c_{\Pi}\left(a_{1}\right)=\left(d\left(a_{1}, C_{1}\right), d\left(a_{1}, C_{2}\right), \cdots, d\left(a_{1}, S_{n-1}\right), d\left(a_{1}, C_{n}\right)\right)=(0,1, \cdots, 2,1)$

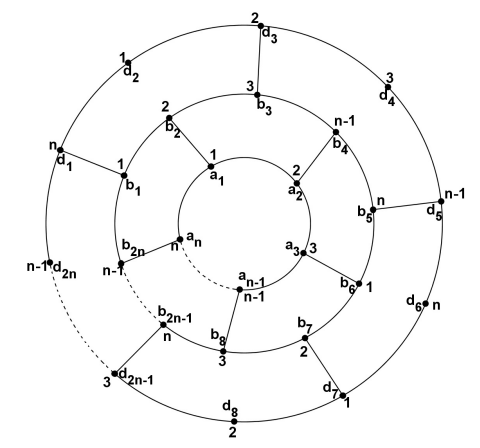

Gambar 9. Graf $\mathrm{C}_{n, 2 n, 2 n}$

$=c_{\Pi}\left(d_{2}\right)=\left(d\left(d_{2}, C_{1}\right), d\left(d_{2}, C_{2}\right), \cdots, d\left(d_{2}, C_{n+1}\right), d\left(d_{2}, C_{n}\right)\right)$, maka kelas warna sebanyak $n$ tidak cukup. Maka banyaknya kelas warna pada graf $C_{n, 2 n, 2 n}$ haruslah $n+1$, atau $\chi_{L}\left(C_{n, 2 n, 2 n}\right)=n+1$.

\section{Kesimpulan}

Pada tugas akhir ini telah diperoleh bahwa bilangan kromatik lokasi dari graf berlapis $C_{n, 2 n, 2 n}$ adalah $n+1$. 


\section{Daftar Pustaka}

[1] Bondy, J.A dan Murty, U.S.R. 1976. Graph Theory with Application. London: The Macmillan Press LTD.

[2] G. Chartrand, D. Erwin, M.A.Henning, P.J. Slater, dan P. Zhang, 2002, The locating-chromatic number of a graph, Bull. Inst. Combin. Appl., 36: $89-101$

[3] G. Chartrand, D. Erwin, M.A. Henning, P.J. Slater, dan P. Zhang, 2003, Graph of order n with locating-chromatic number n-1, Discrete Math., 269: 65 - 79.

[4] Hartsfield, N. dan G. Ringel. 1994. Pearls in Graph Theory: A Comprehensive Introduction, Revised and Augmented. Academic Press, San Diego.

[5] Deo, N. 1989. Graph Theory With Applications To Engineering and Computer Science. New Delhi: Prentice Hall Of India 